\title{
Parameters affecting the selectivity of an electrical insecticide
}

\author{
Lahouaria Neddar ${ }^{1}$, Samir Flazi ${ }^{2}$ \\ ${ }^{1}$ Faculty of Electrical Engineering, Electrical Engineering laboratory of Oran (LGEO), Algeria \\ ${ }^{2}$ Faculty of Electrical Engineering, Mohamed Boudiaf University, Algeria
}

\begin{tabular}{l}
\hline \hline Article Info \\
\hline Article history: \\
Received Apr 28, 2018 \\
Revised Nov 26, 2018 \\
Accepted Dec 21, 2018 \\
\hline
\end{tabular}

Keywords:

Electric current

Electric discharge

Electrical insectitiseur

Harmful flying insects

\begin{abstract}
Using an electrical approach in the field of agriculture can be considered as one of the solutions in order to control harmful flying insects. This technique is based on the use of a bio and selective electrical insecticide whose principle consists in attracting insects by the light then get them electrocuted by an electrical discharge. Moreover, There are several parameters that affect the selectivity of electrical insecticide such as: the light, the most efficient, the inter electrode distance, where the insect is exterminated, and the electric current that passes through the insect's body. In this paper, a simulation study was carried out concerning the distribution of the electric field between two electrodes in presence of particle conductor while focusing on the different body sizes. On the other hand, an experimental study was conducted on live locusts to determine the effect of electrical current on insect's body taking into account the voltage and frequency. Finally, the results are discussed and analyzed in this paper.
\end{abstract}

Copyright (C) 2019 Institute of Advanced Engineering and Science. All rights reserved.

\section{Corresponding Author:}

Lahouaria Neddar,

Faculty of Electrical Engineering,

Electrical Engineering Laboratory of Oran (LGEO), Algeria.

Email: houaneddar@yahoo.fr

\section{INTRODUCTION}

The plant world has been subjected to constant damages by insect pests for millennia. An estimated 30 to $40 \%$ of crops are destroyed each year by insect pests in the absence of pest control. Faced with this dilemma, agriculture specialists tend to intervene by using various methods against insect pests: cultural, biological, and chemical. Until now the most used, if not the only one, are essentially of a chemical nature.

The intensive use of these chemical insecticides either to destroy insect pests or to protect crops has led to the elimination of other non-target species [1] and has affected both the environment and human health (disruption of the nervous system, increase of cancerous diseases, allergies, etc.) [2]. Moreover, the intensification of chemical products has led to a significant change in insect populations and to the appearance of resistance layers which has become a phenomenon that is developing in a worrying way [3], [4]. The increasing usage of chemical doses cannot be separated from human and animal intoxication in a short or long term [5]. Numerous investigations have been undertaken in order to develop another means of exterminating pests without harming the workers and the environment but they have all failed in being selective [6], [7]. Ultimately, developing a selective method which can affect only undesired harmful species without targeting the non-harmful ones is so far regarded as impossible without the use of an electrical approach [8], [9]. This technique is considered as part of a systematic plan against household pests (flies and mosquitoes) [10].

\section{THE PROPOSED APPROACH}

The principles of the electrical approach rely on the attractive effect (lights) and destructive effect (electrical discharge). The system is composed of a high electric voltage circuit responsible for controlling 
the charging and discharging of the capacitors. To facilitate the infiltration of insects inside the device, secured and selective external metal meshes fence are placed in both sides, provided that the mesh size must be equal or superior to the size of the aimed insect. Furthermore, two fluorescents lamps (ultraviolet and green) are used to attract insects to the device. A mechanism for selective destruction is placed inside. It consists of parallel rods connected to a potential difference by an electrical circuit one of which is positively charged (anode) and another with a negative charge (cathode). The rods (forming an electrified fence) are spaced apart to define the inter-electrode gap in which the insects will be electrified then collected by a large bac placed on the bottom. The device has four supports at a certain height supplied with a voltage of $220 \mathrm{~V}$ that can be powered by a photovoltaic system Figure 1 [11].

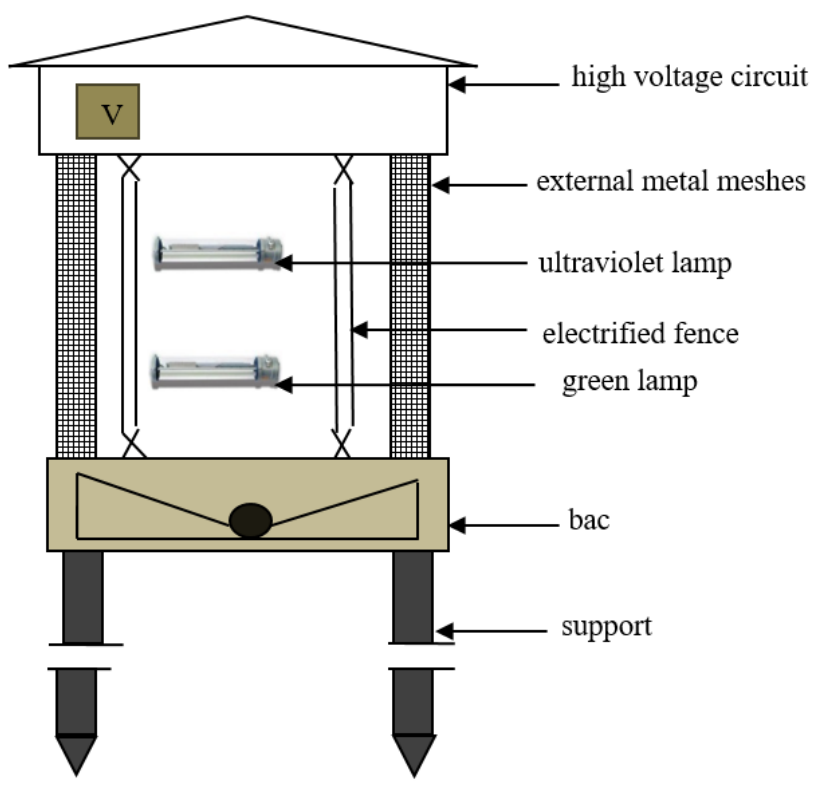

Figure 1. Description of the system

The insects are attracted to the device by the light of the lamp. When they penetrate inside and reach the inter-electrode gap, a breaking air and an electrical discharge are produced. Then, the electric field distribution changes between the insect and the electrode interval. Only insects above a certain size will be electrocuted. The insects will be paralyzed only if the current does not exceed a certain threshold of intensity that depends on the power used and the conductivity of the insect.

However, given the number of interactions between the species present, it makes it difficult to control only the targeted oness hence there is a need to review the influence of some parameters on the selectivity of the system which consists in finding the right and correct values of the parameters that will make the model of control be both specific and selective. Among these parameters, there is an optique parameter (light), electrical parameter (the current through the body of the insect) and the geometric parameter (external metal meshes fence and inter-electrode distance).Very limited research have been undertaken concerning the conductivity of the insects. The electrical properties of biological tissues depend on the conductivity. It was discovered that it exists a transition frequency that is involved in the conductivity which allows the current to pass through the body parts [12], [13].

In the present study, the issue under scrutiny is the parameters that affect on the selectivity of the electrical insecticide. Previous studies have already proven that insects are attracted to light [14], [15]. Concerning the influence of inter-electrode distance on the electric-discharge, a simulation study was performed in the presence of a conductive body. Finally, an experimental study was conducting in the laboratory on live locusts of same weight and size to discover why the insects behave the way they do with the electric current.

\section{RESEARCH METHOD}

The electric field distributions between the two electrodes interrelated to a voltage was performed using a software calling COMSOL version 2 (Multiphysics) to determine the importance of the geometrical 
parts of the bigrille on the rupture of the air gap. The inter electrode distance and the voltage are fixed during the simulation study. Moreover, several measurements were made in order to measure the current under the influence the frequency and voltage. The experimental set is composed mainly of function generator and an ammeter. The measurement of the current was done by planting two electrodes into the body's insect between two points, one of them connected to the alternative generator function type (PM 5192 PHILIPS; $0.1 \mathrm{mHz}-20 \mathrm{MHz}$ ), and the second one to the an ammeter (a measuring device that gives straight forwardly the current value according to the settings). At the beginning, we gradually varied the frequency from $50 \mathrm{~Hz}$ to $900 \mathrm{kHz}$ at fixed $\mathrm{AC}$ applied voltage of $1.76 \mathrm{~V}, 3.5,5.3$ and $7.07 \mathrm{~V}$ ), then we fixed the frequency at $200 \mathrm{KHz}$ and $500 \mathrm{KHz}$ and varied the voltage from $1.76 \mathrm{~V}, 3.5 \mathrm{~V}, 5.3 \mathrm{~V}$ and $7.07 \mathrm{~V}$. These values are in fact imposed by the function generator. With an ammeter, we measured the current passing through the body of insect. In order to determine the effect of parameters simultaneously we suggested an approach that adopts the design of experiments method and which consists of increasing the levels of parameters at the same time during each experimental trial in order to study only certain points of the experimental field which highlight the potential interactions that link these parameters [16], [17] by using the jmp's custom designer version 07 (calculation software for statistical graphics) [18].

\section{RESULTS AND ANALYSIS}

In this section, the results of both simulation and experimental study are explained.

\subsection{Influence of the inter electrode distance}

The electric field distributions change between the two electrodes with the presence of a conductive body. A discharge is produced between one of the electrods and the conducting particle then followed by another discharge between the particle and the second electrode similar to the case of an insect between the anodic and cathode electrodes. There will be two intervals: $\mathrm{d}_{1}$ (anode electrode-body) and $\mathrm{d}_{2}$ (body-cathode electrode). Figure 2 shows the lines changes of the electric field with presence of a conductive particle. The electric field distribution is increasing in the shorter interval « anode-particle » Figure 2 (a). The applied voltage is sufficient to cause a breakdown interval, Figure 2 (b). There is no effect if the particle is smaller than the inter electrode distance, Figure 2 (c). The simulation allowed us to show the influence of the inter electrode distance on the electric field distribution. The more the distance is shorter, the more the discharge is produced. There is a relationship between the configuration of the particle body and inter electrode distance.

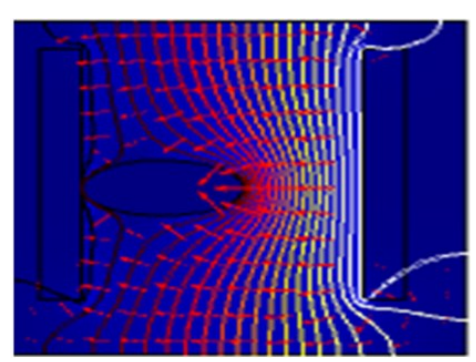

(a)

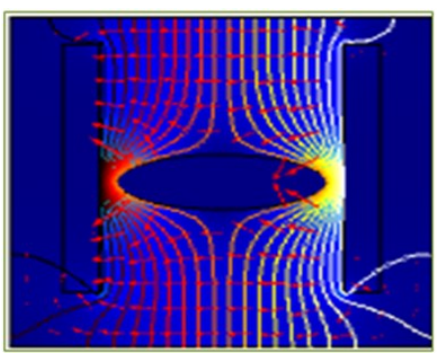

(b)

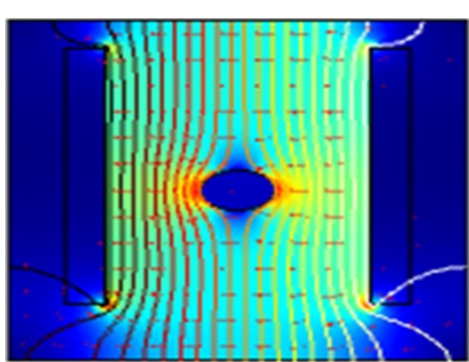

(c)

Figure 2. Changing lines of electric field in the presence of a conductive particle for

(a) first electric discharge between anodic electrode and insect,

(b) the electric discharge between two electrodes, (c) no observable effect

\subsection{Influence of frequency at fixed voltage}

In this section, several measurements were conducted on locusts to discover the influence of the frequency and voltage on the current through the insect's body. The frequency is varied from $50 \mathrm{~Hz}$ to 900 $\mathrm{KHz}$ at fixed applied voltage of $1.76 \mathrm{~V}, 3.5 \mathrm{~V}, 5.3 \mathrm{~V}$ and $7.07 \mathrm{~V}$. Figure 3 shows different threshold of current during the increasing frequency when subjected to applied voltage of $1.76 \mathrm{~V}, 3.5 \mathrm{~V}, 5.3 \mathrm{~V}$ and $7.07 \mathrm{~V}$. It can be deduced that there is no response below $200 \mathrm{KHz}$ for all voltage values used. Beyond the frequence of $200 \mathrm{KHz}$, the insect becomes aware of the flow of electric current through its body. The behavior of the insect varies between perception responses sensations (whiskers movement, paw) to a severe reaction (immobilization). The latest reaction is obtained for $(1.54 \mathrm{~mA} ; 800 \mathrm{KHz})$ for $1.76 \mathrm{~V}$, 
$(1.95 \mathrm{~mA}$; $600 \mathrm{KHz})$ for $3.5 \mathrm{~V},(1.99 \mathrm{~mA} ; 400 \mathrm{KHz})$ for $5.3 \mathrm{~V}$ and $(3.20 \mathrm{~mA}$; $200 \mathrm{KHz})$ for $7.07 \mathrm{~V}$. Figure 3 analysizes the Current threshold according to the frequency of different voltages as explained below: Figure 3 (a) the measurement obtained for $1.76 \mathrm{~V}$ shows that there is a sensation threshold of $0.9 \mathrm{~mA}$ and a frequency of $500 \mathrm{KHz}$. Beyond this frequency, the responses start to become severe followed directly by the immobilization threshold from $1.54 \mathrm{~mA}$ and $800 \mathrm{KHz}$, Figure 3 (b) for a voltage of $3.5 \mathrm{~V}$, we obtained sensation threshold of $1.38 \mathrm{~mA}$ with a frequency of $200 \mathrm{KHz}$. From this level, the thresholds varied to a severe reaction and the insect becomes inactive for $1.95 \mathrm{~mA}$ and $600 \mathrm{KHz}$. Figure 3 (c) for the voltage of $5.3 \mathrm{~V}$, the threshold reaches a severe response of a value of $1.95 \mathrm{~mA}$ and frequency $200 \mathrm{KHz}$ followed directly by the immobilization threshold for $1.99 \mathrm{~mA}$ and a frequency of $400 \mathrm{KHz}$. Figure 3 (d) for $7.07 \mathrm{~V}$, an immobilization is obtained for $3.2 \mathrm{~mA}$ and $200 \mathrm{KHz}$.

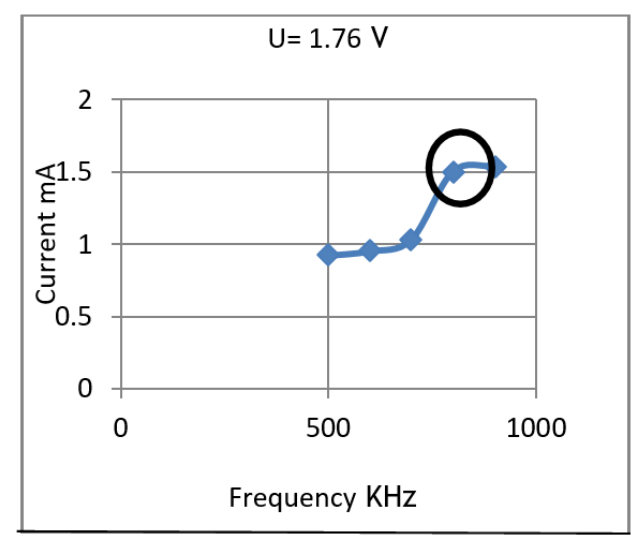

(a)

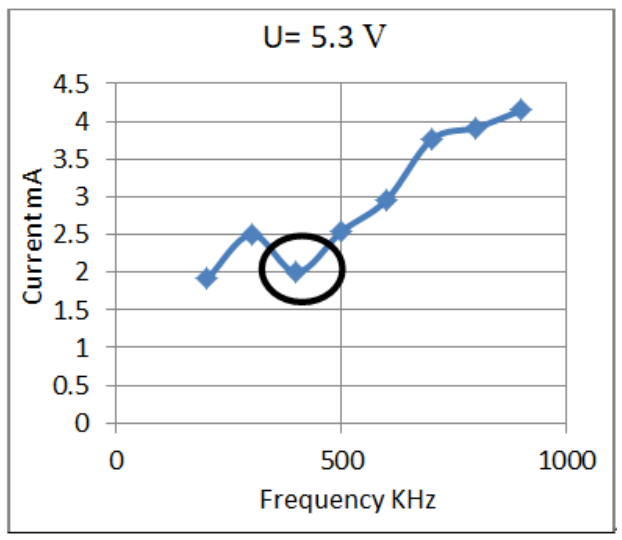

(c)

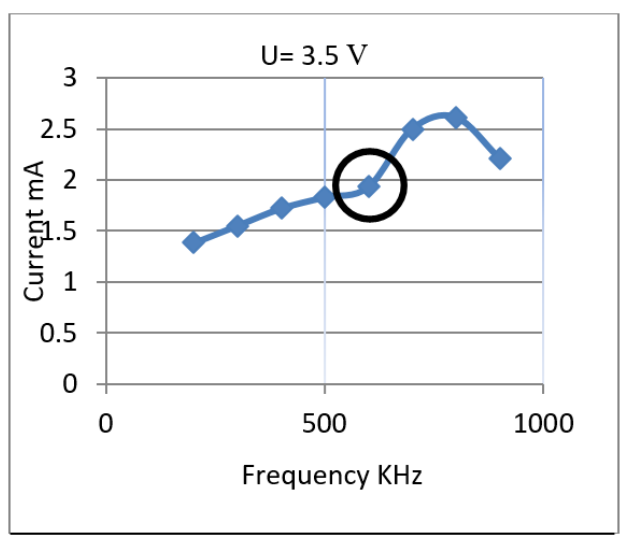

(b)

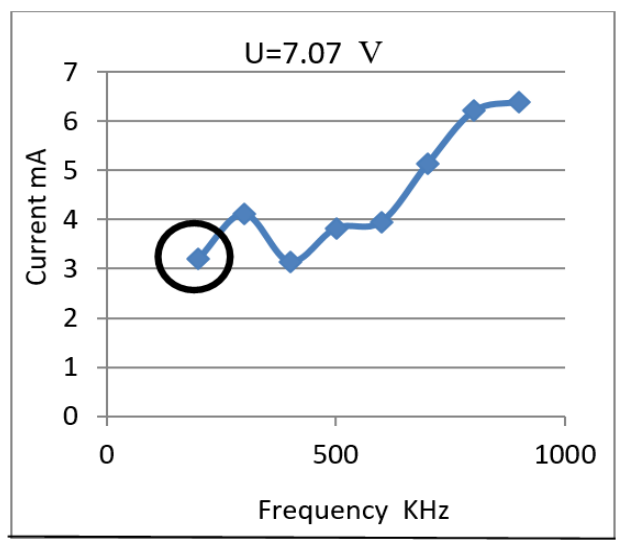

(d)

Figure 3. Current threshold for a voltage of (a) $1.76 \mathrm{~V}$, (b) $3.5 \mathrm{~V}$, (c) $5.3 \mathrm{~V}$, (d) $7.07 \mathrm{~V}$

\subsection{Influence of voltage at fixed frequency}

The measurements consist in varying the voltage from $1.76 \mathrm{~V}, 3.5 \mathrm{~V}, 5.3 \mathrm{~V}$ and $7.07 \mathrm{~V}$ at fixed frequency of $200 \mathrm{KHz}$ and $500 \mathrm{KHz}$. The Figure 4 below shows that the current varies for each frequency. The more the voltage increases, the more the current increases with increasing frequency as well. Figure 4 (a), the insect becomes inactive for $3.5 \mathrm{~mA}$ and $7 \mathrm{~V}$ at frequency of $200 \mathrm{KHz}$. Figure 4 (b), the insect becomes inactive for $2.5 \mathrm{~mA}(5 \mathrm{~V})$ at frequency of $500 \mathrm{KHz}$.

The above results are summarized as follow: No physiological effect was observed below $0.9 \mathrm{~mA}$ in locusts compared to humans, the perception is $0.5 \mathrm{~mA}$ for the frequency of $50 \mathrm{~Hz}$ and it is approximately $12 \mathrm{~mA}$ (man) and $8 \mathrm{~mA}$ (woman) for $10 \mathrm{KHz}$. In livestock no response is observed under $2 \mathrm{~mA}(2 \mathrm{~V})$ for the frequency of $50 \mathrm{~Hz}$ [19], [20]. The threshold current depends of the conductivity of the insect. However, the immobilization of the insect is achieved by varying the frequency or voltage. In order to increase those parameters simultaneously, we suggested an approach that adopts the design of experiments method. 


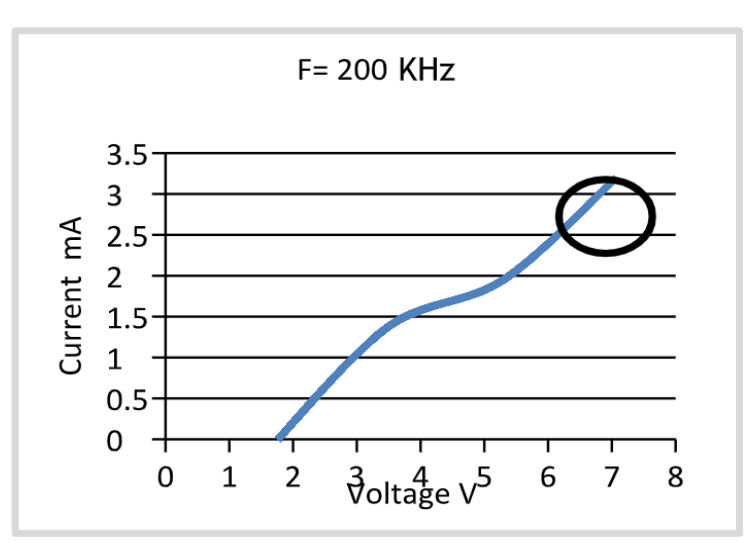

(a)

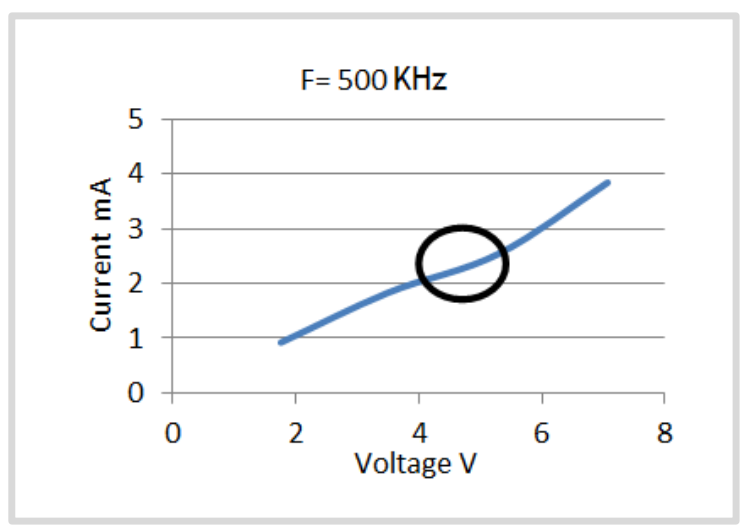

(b)

Figure 4. Current threshold for (a) $\mathrm{F}=200 \mathrm{KHz}$ and (b) $\mathrm{F}=500 \mathrm{KHz}$

\subsection{Influence of frequency and voltage simultaneously}

The simultaneous increase of parameters at each experimental run was performed using the design of experimental method. The later consists in studying only certains points of experimental in order to determine the interaction that links these parameters. The classical measures consisted in determining the level of all variables except one and measuring the response for various values of this variable. It follows that the decision to stop or continue the tests rests mainly on the results obtained gradually, step by step. The variation of the intervals is chosen according to the responses obtained with the preliminary measurements. Table 1 shows the field of study of frequency and voltage between two levels for low level: $200 \mathrm{KHz}$ for the frequency, $3.5 \mathrm{~V}$ for the voltage and high level: $900 \mathrm{KHz}$ for the frequency, 7.07 for the voltage. The frequency of $500 \mathrm{KHz}$ and voltage of $5.3 \mathrm{~V}$ are values at the center of the field. Once the experimental measurements are introduced, the software predicts the responses by using calculation software called jmp (custom designer version 07).

Table 1. The Field of Study

\begin{tabular}{cccc}
\hline Parameters & Low level & center & High Level \\
\hline Frequency (KHz) & 200 & 550 & 900 \\
Voltage (V) & 3.5 & 5.3 & 7.07 \\
\hline
\end{tabular}

The following provides clearly the influence of frequency and voltage simultaneously on the current, which means that the frequency and the voltage have a positive effect on the current, i.e., when one of the parameters decreases, the current is reduced. $2.64 \mathrm{~mA}$ is a coefficient model calculated with the software in the centre of the study for $549.92 \mathrm{KHz}$ and $5.295 \mathrm{~V}$. Figure 5 shows the effect of the parameters simultaneously on the current.

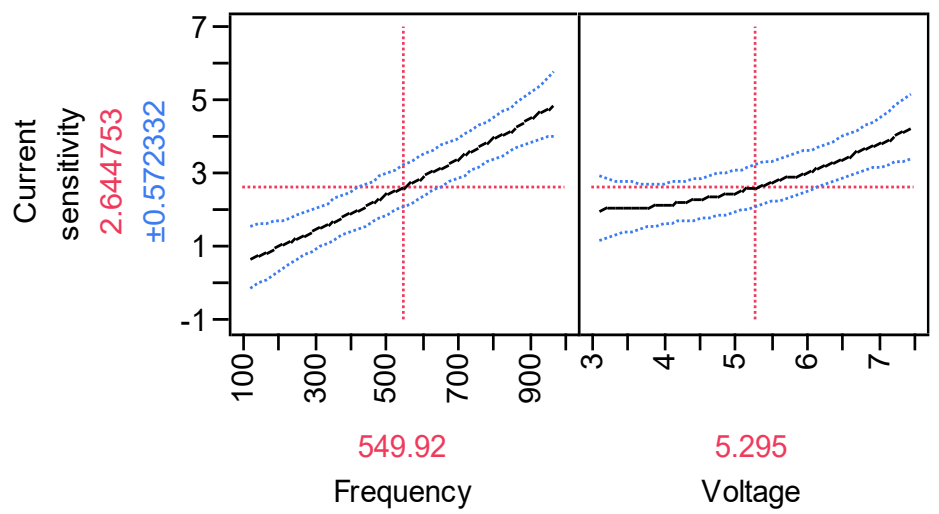

Figure 5. The effect of parameters simultaneously 
Additionally, the software can allow the current to vary by modifying the levels of frequency and voltage by looking for levels that promote the value to be obtained [21]. Figure 6 shows the modifying levels, 3.24 is a predicted value of response changes by dragging a factor value. 705.8 and 4.99:Value of factors changes by dragging the dotted lines.

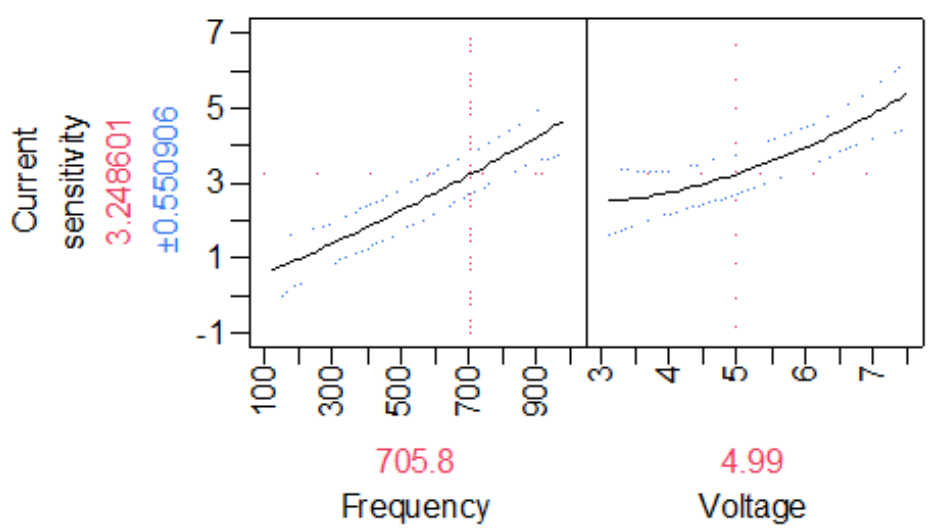

Figure 6. The modifying levels

The result obtained allows us to use a selective and electric system in order to control a certain category of insects compared to other methods which affect all animals. The selectivity of electrical insecticide depends of the inter electrode distance, the mesh size and electric current.

\section{CONCLUSION}

The immobilization of the insect is achieved by varying the frequency or voltage. As a matter of fact, the increase of factors simultaneously with the design of experimental method showed easier and precise results and proved that frequency is more significant than a voltage. The insects'sensitivity to current depends of these parameters. The electrical system has many advantages that could be interesting than the chemical method and other methods already used due to the reasons that it is considered as non pollutant, nontoxic, selective, can be monitoring nearby and be powered with a photovoltaic system.

We are considering carrying out theoretical and experimental studies focusing on other types of insects other than locusts. The development of a selective strategy could be widely used only if researchers in the fields of biology and electricity combine their efforts to develop an advanced affordable technology.

\section{ACKNOWLEDGEMENTS}

This work would not have been possible without the help and suggestions of Professor Flazi samir. I am also grateful to all staff of High Voltage Laboratory, University of Oran with whom I have had the pleasure to work. Finally, completing this work would have been all the more difficult were it not for the support provided by the technicians of the Laboratory of Department of Electrical Engineering of Mostaganem.

\section{REFERENCES}

[1] B. Ndakidemi, "Impacts of Synthetic and Botanical Pesticides on Beneficial Insects," Department of Water and Environmental Sciences (WESE), The Nelson Mandela African Institution of Science, Agricultural Sciences, 7, 364-372, 2016.

[2] Consoglobe, "Cancer and pesticides," 2009.

[3] J.Hoffmann, "Immunity defense mechanisms of insects," in The receiver Toll, 1996.

[4] M. Sarwar. and M. Salman., "Insecticides Resistance in Insect Pests or Vectors and Development of Novel Strategies to Combat Its Evolution," International Journal of Bioinformatics and Biomedical Engineering, Vol. 1, No. 3, pp. 344-351, 2015.

[5] Muller. B, "Impacts of sublethal insecticide exposure on insects-Facts and knowledge gaps," Journal of AsiaPacific Entomology: Basic and applied ecology, volume 30, pp1-10, 2018. 
[6] Mamadou. A, et al., "The impact of pesticides used in locust control (schistocerca gregaria Forskål,1775) (orthoptera, acrididae) on two species of pimelia (coleoptera, tenebrionidae) in Niger," Vertigo, The Journal of Environmental Science, Vol 6, no3, 2005.

[7] ANONYME, 1993 "Control desert Locust by existing techniques, assessment of strategies," Compte rendu du séminaire de Wageningen, Pays Bas, $140 \mathrm{p}$.

[8] S. Flazi, et al., "Using high voltage to control agricultural flying harmful insects," International Conference Study on Organic Agriculture and Rural Development. AGROBIO, 2011.

[9] L.Neddar, et al., "Using electrical approach to control agriculturale harmful flying insects," International Electrotechnical Day, JIEMCEM, 2010.

[10] M . Bitner, "Electronic destroyers of flying insects," in food-processing industries, 1998.

[11] L. Neddar, "A bio electrical strategy for the destruction of flying agricultural harmful insects," personnel communication. In: Japan Academic Symposium Sustainable Society through Advanced Sciences, USTO-MB, Oran, Algeria, May $17^{\text {th }}, 2012$.

[12] D.Miklavcic and N.Pavselj, "Electric properties of tissues," in Wiley Encyclopedia of Biomedical Engineering, 2006.

[13] S.Grimnes and O.Martinsen, "Bioimpedance and bioelectricity," Basics, Academic Press. $3^{\text {rd }}$ edition, 2008.

[14] Baird .E , et al., "Visual control of flight speed in honeybees," Journal of Experimental Biology, vol. 208, 3895$3905,2005$.

[15] Kennedy . J.S , "Visual responses of flying mosquitoes," Journal of Zoologie, vol. 109, pp. 221-242, 1940.

[16] J.Goupy, "Practise the design of Experiment method," Edition Dunod, 2005.

[17] J.Goupy, L. Creighton, "Introduction of designe experiment method," Editions Dunod, 2006.

[18] Jmp Introductory Guide Version 7 of JMP. Cary, NC, (SAS Institute), Inc., 1989.

[19] IEC, "Effects of current on human beings and livestock," Technical Report, 60479-1. $4^{\text {th }}$ edition, 2005.

[20] Technical Report, "Effects of currents passing through the body of livestock," (IEC). $1^{\text {th }}$ edition, 1998.

[21] Y.Dodge,V. Rousson, “Applied of regression analysis,” Dunod, Paris, 2004.

\section{BIOGRAPHIES OF AUTHORS}

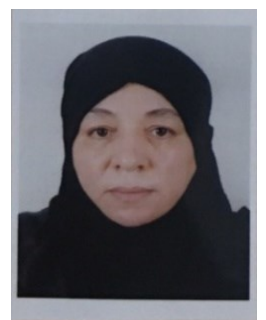

Lahouaria Neddar received the B.E degree in Electrical Engineering from Oran Univeristy (Algeria) in 1990. She worked as an engineer in Public Community Lighting Company, Oran, (Algeria) in 1991. In 1996 she received a diploma in Information Technologies in London School of Science \& Technology, London (UK). In the same year she worked as a Technical Consultant in Gulf Connection, London (UK). From 2000-2002 she worked as a technical engineer for Safina Group, Mostaganem (Algeria). She worked as a laboratory engineer in Mostaganem University. She received the MA degree in Electrical Discharge and High Voltage from Oran University (Algeria) in 2005. She works at University of Science and Technology of Mostaganem (Algeria) since 2006. She is a professor at the faculty of Electrical Engineering and a member of the Electrical Engineering laboratory of Oran supervised by Professor Samir Flazi. Her research interests are Electrical Discharge and High Voltage, and Renewable Energies.

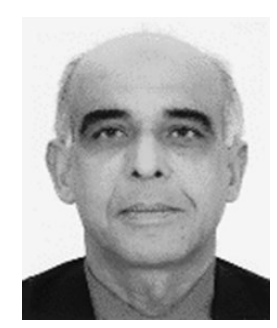

Professor Samir Flazi was born in 1950. He received the B.E degree in electrical engineering from Aleppo University (Syria) in 1973, the D.Eng. and PhD degree from Paul Sabatier university, Toulouse, French, in 1981 and 1987 respectively. He works at university of Science and Technology of Oran, Algeria since 1979; he is a professor of the faculty of electrical engineering and head of research team at electrical engineering laboratory of Oran. His research interests are high voltage, electric network and electrostatics, responsible for several research projects and author of an electrical terms dictionary English-French-Arabic. He is a member of an AlgerianJapanese project Sahara Solar Breeder (SSB) project, (Algerian side), responsible of local PV application and grid connection team, high temperature superconductor cables ( $\mathrm{HTcSC})$ team and PhD course. 